\title{
EL INSTITUTO ESPAÑOL DE ENTOMOLOGÍA (CSIC) Y LA MULTITUD MOLESTA $^{1}$
}

\author{
Carolina Martín Albaladejo \\ Museo Nacional de Ciencias Naturales, CSIC. José Gutiérrez Abascal, 2. Madrid 28006 España \\ carolina.martin@mncn.csic.es \\ Antonio Notario Gómez \\ Escuela Superior de Ingenieros de Montes, Madrid. Ciudad Universitaria, s/n. Madrid 28040 España \\ antonio.notario@upm.es \\ Alfonso V. Carrascosa Santiago \\ Museo Nacional de Ciencias Naturales, CSIC. José Gutiérrez Abascal, 2. Madrid 28006 España \\ av.carrascosa@csic.es
}

Recibido: 14 noviembre 2014; Aceptado: 6 mayo 2015.

Cómo citar este artículo/Citation: Martín Albaladejo, Carolina; Antonio Notario Gómez y Alfonso V. Carrascosa Santiago (2016), “EI Instituto Español de Entomología (CSIC) y la multitud molesta", Asclepio 68 (1): p125 doi: http://dx.doi.org/10.3989/asclepio.2016.04

RESUMEN: En 1941 se creó el Instituto Español de Entomología (IEE), heredero directo de la antigua Sección de Entomología del Museo Nacional de Ciencias Naturales. Entre las labores encomendadas al nuevo establecimiento estaba la de aportar «a los Centros de aplicación los datos resultantes de los trabajos que en él se efectúen con los insectos, de interés económico y sanitario». Gonzalo Ceballos fue nombrado Director y sus propuestas, junto al trabajo de las instituciones encargadas de la gestión forestal, hicieron del IEE uno de los centros motores de muchas iniciativas en este campo. Su dirección supuso, además, una excelente oportunidad para cumplir los objetivos con los que fue concebido el Instituto. En este artículo se distinguen tres formas de participación respecto al estudio, gestión y control de plagas forestales. Por un lado, la implicación del IEE en la resolución de consultas de particulares, empresas e instituciones; en segundo lugar, el desarrollo de proyectos subvencionados por el Patronato Juan de la Cierva y, finalmente, las colaboraciones con diferentes cuerpos dependientes del Ministerio de Agricultura. Se constata que la falta de personal especializado en plagas adscrito al IEE supuso un grave inconveniente para que las iniciativas de Ceballos se desarrollaran más allá de su gestión.

PALABRAS CLAVE: Historia del Consejo Superior de Investigaciones Científicas; Instituto Español de Entomología; Gonzalo Ceballos; Entomología aplicada; Plagas forestales.

\section{THE SPANISH INSTITUTE OF ENTOMOLOGY (CSIC) AND THE BOTHERED CROWD}

ABSTRACT: The Spanish Institute of Entomology (IEE) was founded in 1941, direct heir of the former Entomology Section of the National Museum of Natural Science. Among the tasks assigned to the new Institute was to provide "to the interested centers the data resulting from the work that he made with insects with economic and public health significance". Gonzalo Ceballos was appointed Director; his proposals, alongside the work of the institutions responsible for forest management, turned up the IEE into one of the driving forces of many initiatives in this field. His management also provided an excellent opportunity to meet the objectives for which the Institute was conceived. Three forms of participation were distinguished on the study, management and control of forest pests. On one hand, the involvement of the IEE in resolving queries from individuals, companies and institutions; second, the development of scientific projects supported by the Juan de la Cierva Board of Trustees and, finally, collaborations with different departments belonging of the Ministry of Agriculture. It is stated that, the lack of specialized personnel assigned to the IEE pests' management was a serious drawback to continue the initiatives of Ceballos be developed beyond management.

KEY WORDS: History of Spanish National Research Council; Institute of Entomology Spanish; Gonzalo Ceballos; Applied entomology; Forest pests.

Copyright: () 2016 CSIC. Este es un artículo de acceso abierto distribuido bajo los términos de la licencia Creative Commons Attribution (CC BY) España 3.0. 


\section{INTRODUCCIÓN}

"...decimos una plaga indicando familiarmente una multitud molesta..."

Idea general de plaga (Ceballos, 1941-1942)

El Instituto Español de Entomología (IEE) fue fundado tras el desmembramiento del Museo Nacional de Ciencias Naturales (MNCN) al término de la guerra civil española, integrando en el nuevo centro las colecciones, biblioteca y personal que antes había sido la Sección de Entomología del Museo. Esta Sección que durante tantos años protagonizó los estudios entomológicos españoles, se quedó sin muchos de los investigadores que la formaban, como Ignacio y Cándido Bolívar, Dionisio Peláez o Juan Gil Collado (Gomis, 2014) y el nuevo gobierno, tras la puesta en marcha del que iba a abanderar la investigación científica en España, el Consejo Superior de Investigaciones Científicas (CSIC), creo en $1941 \mathrm{el} \mathrm{IEE}^{2}$ que en «el marco de la investigación pura, pueda favorecer eficazmente la labor encomendada a los servicios que en distintos sectores, sanitario, agrícola, forestal, pecuario, luchas contra los daños producidos por los insectos». Nació así un Instituto con vocación en la investigación de tipo aplicado, «justificado científica y económicamente por la magnitud e interés excepcionales de este grupo de seres naturales [los insectos], que sustraen anualmente a nuestra riqueza cientos de millones de pesetas» y constituido "en tres Secciones: Sección de Entomología general, Sección de Entomología agrícola y Sección de Entomología forestal»³.

En este trabajo se examinan las actividades que bajo esta última línea de investigación, la Entomología Forestal, se desarrollaron en el IEE en la etapa de su primer director, Gonzalo Ceballos (1895-1967), ingeniero de montes al que siempre le atrajeron los insectos como organismos interesantes por sí mismos y no solo como criaturas susceptibles de causar daños en masas forestales. Ceballos estuvo desde joven vinculado al MNCN, relacionándose con Ignacio Bolívar y su equipo de entomólogos (Cándido Bolívar, José María Dusmet, Manuel Martínez de la Escalera). Ganó por oposición la Cátedra de Zoología y Entomología de la Escuela Especial de Ingenieros de Montes de Madrid en 1934, donde fue profesor hasta su jubilación. Más datos sobre su biografía en Agenjo (1967), M.G.V. (1968a, 1968b); Soria \& Cobos (1990); Notario Gómez (2008), Otero Carvajal \& López Sánchez (2012). Su primera veintena de trabajos publicados corrobora su más que afición a la Entomología básica, todos ellos dirigidos al estudio taxonómico de un grupo especialmente complicado como son los himenópteros ichneumónidos, del que no había ningún especialista en España; son trabajos que publicó desde 1920 a 1941. En este último año apareció el primero dedicado a tratar un aspecto aplicado, Idea general de la plaga producida por insectos (Ceballos, 1941) donde el autor resume su idea de plaga «decimos una plaga indicando familiarmente una multitud molesta». Es también en 1941 cuando le nombran Director del recién creado IEE, centro que se pretendía fuese «...un primer brote especializado con proyección de la "labor científica sobre problemas de interés social y económico"...»".

Los objetivos de este nuevo centro aspiraban hacia los mismos fines que el organismo que lo sostenía:

[Los fundadores del CSIC] También quieren que ese nuevo organismo activamente promueva y renueve centros e inicie líneas de investigación en disciplinas sin tradición o presencia activa en el Estado, empezando de cero si es necesario, o eliminando lo que estorbe. El nuevo organismo ha de ocuparse, muy especialmente, de fomentar la tecnología y las ciencias aplicadas (Malet, 2008).

No era nueva la idea de que los científicos que se ocupaban de la Entomología de tipo general se involucraran en su vertiente de tipo aplicado. Ya en 1922, el Ministerio de Fomento publicaba un Real Decreto en el que solicitaba para el Laboratorio de la Fauna Forestal Española la colaboración de "otros elementos útiles de investigación, de notoria autoridad en sistemática, que cual el Museo Nacional de Ciencias Naturales pueden contribuir por sus especialistas a un mayor rendimiento de trabajo». Ignacio Bolívar, Director del MNCN, aceptó con interés el requerimiento, resultando elegidos para esa colaboración Ricardo García Mercet y Cándido Bolívar ${ }^{6}$ (Otero Carvajal \& López Sánchez, 2012). Abundando en este sentido, indicaremos que en 1929 y 1930, Ignacio Bolívar solicitó a la Dirección General de Montes, Pesca y Caza, la incorporación de Gonzalo Ceballos en el MNCN como colaborador pues

vendría a iniciar en nuestro país la estrecha colaboración entre los técnicos que estudian la Entomología aplicada y los que laboran en ella como Ciencia pura, colaboración que existe en otros países, como los Estados Unidos, donde muchos de los técnicos del Bureau of Entomology están permanentemente agregados a la Sección de Entomología del U.S. National Museum, por haberse percatado oportunamente la dirección del Bureau of Entomology de las ventajas que una colaboración de esta índole tiene forzosamente que proporcionar $^{7}$ (Otero Carvajal \& López Sánchez, 2012).

Esta petición de colaboración ya fue formulada en 1928 en la revista España Forestal (Anónimo, 1928). 
Gonzalo Ceballos, como Director del nuevo centro, aunó los propósitos con los que nació éste y sus propios intereses investigadores. Era por tanto, un perfil muy adecuado para la gestión del nuevo Instituto. El mandato de Gonzalo Ceballos en el IEE se extendió durante los 26 primeros años de vida del Instituto y las actividades que realizaron en el área de la entomología aplicada fueron muchas y de índole muy diversa, algunas de gran interés por ser las primeras de su tipo que fueron ejecutadas en España. Además, como se verá más adelante, hubo una elevada implicación del IEE, a través de su Director, en la estructuración de las instituciones que se ocuparían de la gestión de plagas forestales en España.

\section{PRIMEROS PASOS DEL IEE EN ENTOMOLOGÍA APLICADA}

En los primeros años de vida del IEE las labores en el área de la Entomología aplicada se limitaron a dar respuesta a consultas puntuales de particulares, empresas e instituciones oficiales. AI IEE llegaban solicitudes requiriendo la identificación de insectos y desde el Instituto se responde con informes donde no sólo se identificaba la plaga sino que se aconsejaba sobre cómo erradicarla y prevenir nuevos casos. La primera consulta que nos encontramos es la que realizó en diciembre de 1941 el Ingeniero Jefe del Servicio Agronómico de los Territorios Españoles del Golfo de Guinea, quien envía desde Santa Isabel, Fernando Poo (Guinea Española $)^{8}$, una muestra de parásitos del café. Tras esta remesa encontramos a Luis Báguena, médico y entomólogo, quien ya se relacionaba con Ceballos en el periodo en que ambos colaboraban con la Sección de Entomología del MNCN. Báguena trabajaba entonces como entomólogo para el Servicio Agronómico de los Territorios Españoles del Golfo de Guinea y desde allí se realizan, al menos hasta 1946, varios envíos al IEE con muestras de insectos para identificar:

Por el presente correo me permito remitirle al Instituto de Entomología, un nuevo pequeño lote de parásitos, por si ahí pueden determinarlos. Se trata de un hemíptero que daña las hojas del café, de un Syrphidae? con su pupario, que es parásito de la larva de un cerambycido que barrena los troncos del árbol de la Kola, y de otro díptero que parasita a su vez al parásito de la palmera del aceite ${ }^{9}$.

Otras corporaciones que consultaron al IEE son, por ejemplo, los Distritos Forestales de Barcelona, Córdoba, Gerona y Madrid; la División Hidrológica Forestal de Madrid; la Hermandad de Labradores de la ciudad de Toro (Valladolid) o el Instituto Español de Medicina Colonial. Pero no son solo instituciones dedicadas a la producción agrícola o forestal sino que también fueron otras las que acudieron al IEE en busca de identificación y asesoramiento para la eliminación de insectos dañinos; así, les consultó el Arquitecto Conservador de la Alhambra por un problema de Galerucella en los olmos del recinto ${ }^{10}$; el Ayuntamiento de Burgos, que también tenía un problema de infestación de sus olmos por ese mismo coleóptero crisomélido, la Galerucella luteola ${ }^{11}$ o el Ayuntamiento de Orihuela del Tremedal, Teruel. En 1947 fue el Capitán General de Madrid, Agustín Muñoz Grandes, a quien se le remitió un informe sobre plaga de insectos en el campamento de Carabanchel (plaga en chopos por Aegeria apiformis L., Melanophila picta Pall. y Anoxia villosa F.). Como en otras ocasiones, también se aportaban datos biológicos de las especies implicadas y posibilidades para combatirlas. Además, se les indicó que:

se está dispuesto, si así interesa, a realizar ensayos de terapéutica combinada intensiva, siempre que se le faciliten medios de locomoción y mano de obra auxiliar, proporcionando los productos necesarios y material correspondiente ${ }^{12}$.

Un aspecto que creemos interesante resaltar es que el IEE no sólo determinó las muestras sino que en sus informes solía aportar numerosos datos acerca de la especie a la que se refería, su biología, distribución, potencial como plaga, posible infestación, daños, enemigos naturales, medios de lucha, etc. Es decir, se intentaba colaborar en lo posible a la solución del problema.

\section{EL IEE Y EL PATRONATO JUAN DE LA CIERVA}

Las actuaciones del IEE, en cuanto a plagas forestales se refiere, tomaron impulso en 1946, año en el que comenzó una fructífera relación con el Patronato Juan de la Cierva. Mientras que anteriormente las ayudas a particulares e instituciones eran de carácter puntual, es decir, sin que existiese un proyecto general bajo cuya cobertura se trabajase, en 1946 se planteó un programa específico que fue subvencionado por el Patronato Juan de la Cierva, Patronato que había sido creado con la misión de "organizar y dirigir la investigación hacia objetivos utilitarios, de carácter militar e industrial» (López García, 1997). Ceballos consiguió así un apoyo pecuniario siguiendo las líneas que el CSIC deseaba favorecer,

...el CSIC promovió la investigación aplicada y tecnológica. Para ello, no sólo consiguió del INI cuantiosos recursos para el Patronato Juan de la Cierva, sino que desequilibró los presupuestos de sus institutos de ciencias en detrimento de la investigación pura y en favor de la aplicada (Malet, 2008). 
El proyecto en el que se centró el IEE, con su director y secretario al frente, Gonzalo Ceballos y Eduardo Zarco ${ }^{13}$ respectivamente, fue el de la investigación y control de plagas de insectos en viveros forestales, un proyecto íntimamente relacionado con el Plan General de Repoblación Forestal de España (1939). Luis Ceballos, hermano menor de Gonzalo, y Joaquín Ximénez Embún fueron los que elaboraron este proyecto en el que se proponía la reforestación de España con los objetivos de:

1.- Elevar la productividad de los montes que nos quedan; 2.- Repoblar todos los rasos de los montes hoy catalogados como de utilidad pública; 3.- Crear todos los montes que además de los existentes son indispensables para conseguir un buen régimen hidráulico; 4.- Crear los que todavía puedan ser precisos para satisfacer las necesidades nacionales de consumo de productos forestales, y 5.- Crear todavía aquellos otros, que con sus productos, viniesen a sustituir con ventaja, el servicio que hoy prestan a la agricultura y a la ganadería. (Ximénez de Embún \& Ceballos, 1996).

Una medida que pudo ayudar para alcanzar el propósito del Plan General de Repoblación Forestal de España, en el que se planteó la repoblación de 6 millones de Ha en 100 años, fueron los sistemas de cultivo de las plantas en viveros, ya que podían garantizar la obtención de ejemplares arbóreos de calidad y en poco tiempo. En un informe al Patronato Juan de la Cierva de septiembre de 1946, Ceballos aportó datos de las cuantiosas pérdidas que las plagas de insectos originaban en los viveros a lo largo de todo el territorio español. En concreto advertía acerca de las pérdidas del Distrito Forestal de Córdoba, Logroño o Santander y de la División Hidrológica de Zaragoza y de Sevilla, entre otros. Y continuaba notificando que «ha emprendido una serie de estudios y ensayos encaminados a la posible solución del mismo ${ }^{14}$. Fue este un proyecto que combinaba tratamientos terapéuticos, tanto combativos como preventivos y en el que se hacían ensayos controlados en laboratorio esperando encontrar pautas que pudieran más tarde dar buenos resultados en la masa forestal del país.

Con la primera subvención que el Patronato Juan de la Cierva concedió al IEE, se realizaron en Córdoba y Santander (viveros de Alcolea y Villapreste):

ensayos que tendían a determinar, al mismo tiempo que el poder tóxico efectivo del insecticida sobre la larva del insecto, las dosis tolerables del mismo por parte de la planta ${ }^{15}$.

Así comenzaron una serie de programas periódicos desde 1946 a 1948 en los que el IEE obtuvo subvenciones de 80.000 ptas. anuales con el objetivo de conseguir la erradicación de las plagas de insectos en viveros forestales. Para la consecución de este trabajo se pusieron en contacto con 34 viveros repartidos por una gran parte de España.

Gonzalo Ceballos y Eduardo Zarco fueron los únicos responsables del proyecto. Fueron ellos los que escribieron a los viveros solicitando muestras, controlaron los envíos que se realizaban al IEE para la identificación de los insectos, elaboraron informes, etc., efectuando un completo seguimiento del proceso ${ }^{16}$. También fueron ellos los que, a lo largo de estos años, sugirieron la forma de combatir las plagas detectadas en los viveros, cultivos controlados de plantas donde crecían alrededor de veinticinco especies vegetales (acacias, álamos, arces, castaños, chopos, cipreses, encinas, olmos, palmitos, pinos, robles, tilos). Se complementó el proyecto, como se ha indicado anteriormente, con la realización, en pequeñas parcelas, de ensayos para determinar el potencial tóxico del producto insecticida sobre los insectos y las dosis de éste que la planta podía aceptar.

Además de los proyectos dedicados al control de plagas de insectos en viveros, colaboraron en la erradicación de la lagarta (Lymantria monacha L.) en pinares de Pinus silvestris L., cuando el Distrito Forestal de Teruel pidió ayuda en $1948^{17}$. Se recogieron millares de huevos en diversas zonas de España y se criaron en la Estación de Ensayos de El Ventorrillo con objeto de ver qué parásitos emergían de ellos y estudiar si podrían ser utilizados como control biológico de la plaga. Esta Estación, que venía siendo gestionada por el IEE desde 1944, fue creada por Ignacio Bolívar en 1910 como Estación Alpina de Biología, y se encontraba localizada en la Sierra del Guadarrama, cerca del Puerto de Navacerrada, donde hoy sigue. También en el Insectario ${ }^{18}$ del IEE, una pequeña casita que aún hoy se conserva en los jardines del MNCN, se criaron diversas especies de insectos de interés forestal.

Al ser la lagarta una plaga de muchos pinares del territorio español, resolvieron emplear un recurso que ya entonces se utilizaba en Alemania y Norteamérica, el uso de aviones para fumigar grandes extensiones de masas forestales. La experiencia se realizó en Pinar Grande (Soria) en colaboración con la Dirección General de Montes del Ministerio del Aire y el instituto de Técnica Aeronáutica ${ }^{19}$ y se trató de la primera de este tipo ejecutada en el país (Rupérez, 1958). En 1950 se ejecutaron las primeras fumigaciones aéreas con un aparato «Miles Aerovan», sobre el que se montó un dispositivo encargado de la distribución del insecticida, módulo que había sido ideado por personal del $\mathrm{IEE}^{20}$. En 1953 las fumigaciones se hicieron con un 
trimotor "Junkers», con el que se sobrevolaron los pinares de Guadarrama; a esta exhibición acudió el Jefe del Estado Francisco Franco (Figura 1), como se recoge en el Boletín Informativo del Instituto de Ingenieros Civiles de España (Anónimo, 1953). Hubo otras tentativas para erradicar esta plaga como la de intentar obtener un aparato que producía «nieblas» de insecticidas desde tierra, ensayos para su fabricación ${ }^{21} y$ la construcción de un motor-compresor.

Figura 1: Francisco Franco y Gonzalo Ceballos en una exhibición de fumigaciones aéreas contra la plaga de la lagarta en Pinar Gordo (Soria). Imágenes publicadas en el Boletín Informativo del Instituto de Ingenieros Civiles de España (1953).

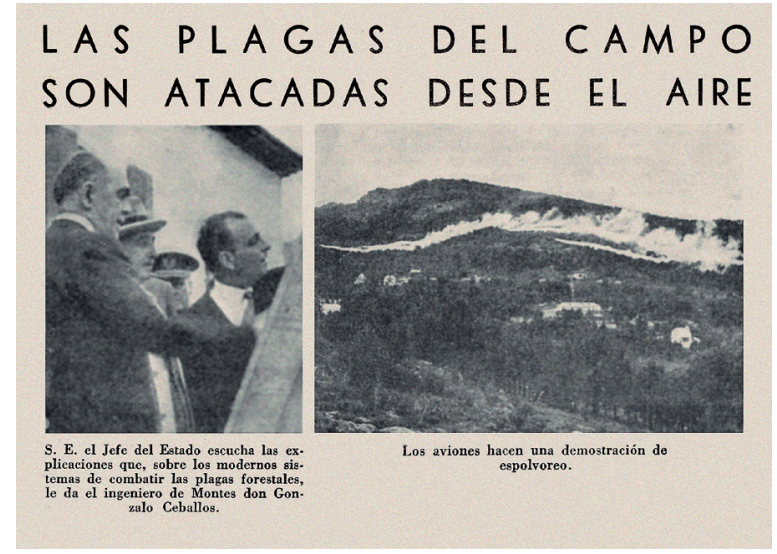

Otro de los insectos del que se ocuparon fue el himenóptero Diprion pini (L.), localizado al examinar la plaga de Lymantris monacha $\mathrm{L}$. en los pinares de Teruel. Advirtieron que estaba atacando los bosques y aprovecharon las distintas experiencias en su combate para realizar un «film documental $»^{22}$ donde plasmar los aspectos biológicos de la plaga. El Instituto de Investigaciones y Experiencias Cinematográficas, cuya sede se encontraba en el mismo edificio que el IEE, el Palacio de la Industria y las Artes, actual sede del MNCN, colaboró en la realización de un reportaje sobre este insecto. El film, dirigido por Eduardo Zarco:

constituye un primer ensayo en el campo de la cinematografía científica, muy aleccionador, [...] ya que su difusión entre el personal encargado de su vigilancia y conservación de nuestros bosques [...] permita en el futuro salvar grandes cantidades de árboles de la voracidad de los insectos, como Ceballos deja reflejado en la Memoria de 1949 para el Patronato Juan de la Cierva (Ceballos, 1950).

Aprovechando las imágenes que Luis Esteban Matamala, dibujante del IEE, realizó para el documental, también editaron una publicación ilustrada (Ceballos \& Zarco, 1952) donde relataban tanto la biología y desarrollo de estos insectos, como sus parásitos, la manera en que se operó para su erradicación y los diversos ensayos que se hicieron para su eliminación.

A partir de 1955 se detectó un cambio en la orientación de los proyectos de investigación del IEE sobre plagas forestales; el giro se tradujo en una mayor atención a temas de biología básica, dejando un tanto apartada su implicación práctica en objetivos de tipo aplicado. Aun así, Ceballos insistió en que se trataba de investigaciones sobre «insectos de indudable interés forestal $»^{23}$. Se sucedieron los estudios de especies implicadas en daños a masas forestales. Gonzalo Ceballos y Eduardo Zarco, junto a Domingo Cadahía Cicuéndez, Juan Miguel Gómez-Menor Guerrero, Luis Esteban Matamala, Manuel Sánchez y Margarita Vogel profundizaron en el conocimiento de la fauna asociada al chopo (Zarco \& Ceballos, 1956) en España, incluidos sus parásitos y depredadores ${ }^{24}$. Se estudiaron especies de lepidópteros como Sesia apiformis y Paranthrene tabaniformis (Rott.) (Cadahia, 1958), homópteros como Pemphigus spirothecae Pass. (Gómez-Menor Guerrero, 1957a) y tisanópteros como Ecacanthothrips nodicornis (Reut.) (GómezMenor Guerrero, 1957b). Los resultados de estas investigaciones se publicaron en muchos casos en la revista Graellsia ${ }^{25}$, uno de los órganos de difusión del IEE. También en publicaciones del Patronato Juan de la Cierva, como la obra «Ensayo de lucha biológica contra una plaga de Diprion pini (L.)» (Ceballos \& Zarco, 1952) o "Insectos perjudiciales al chopo en España» (Zarco \& Ceballos, 1956). Otros estudios tuvieron como protagonistas a los lepidópteros Ocnerostoma piniariella Z., y sus parásitos, plaga observada en masas de Pinus silvestris; y a una nueva especie del género Cossus que afectaba a los chopos.

El último año que el IEE percibe subvenciones del Patronato Juan de la Cierva es 1958. En esta ocasión Juan Gómez-Menor Ortega estudió la fauna cocidológica de los encinares españoles y la variabilidad de algunas especies de homópteros; Ramón Agenjo y Domingo Cadahía, centraron su labor en los lepidópteros que atacaban encinas, sobre todo las especies del género Catocala (Noctuidae); Luis Báguena realizó aportaciones en el grupo de los coleópteros; Eugenio Morales Agacino recopiló información sobre diversos problemas entomológicos ${ }^{26},{ }^{27}$; Juan Miguel GómezMenor Guerrero se formó en la recolección y preparación de materiales para estudios sobre lucha biológica y Antonio Varea Cortés dio apoyo como preparador. 
Estos trabajos dieron como resultado la publicación de cuatro originales que conformaron una monografía, Trabajos de Entomología Forestal28 (VVAA, 1957).

\section{EL IEE Y EL MINISTERIO DE AGRICULTURA}

En 1952 el Ministerio de Agricultura, dirigido por el ingeniero agrícola Rafael Cavestany de Anduaga, fundó una sección dedicada a las plagas que afectaban a las masas forestales, el Servicio Especial de Plagas Forestales, dependiente de la Dirección General de Montes, Caza y Pesca Fluvial. Esta nueva sección se implantó «bajo el estímulo de Gonzalo Ceballos y tras la realización de un exhaustivo informe sobre el estado fitosanitario de nuestros bosques» y debía encargarse de:

la detección de plagas, la identificación de insectos y hongos forestales, el estudio de las poblaciones de plagas y de sus enemigos naturales y los experimentos con plaguicidas y sus efectos secundarios (Pajares Alonso, 2009)

Gonzalo Ceballos deseaba que su Instituto formara parte de esta nueva iniciativa y en 1955 remitió al Patronato Juan de la Cierva un informe titulado «Proyecto de organización de laboratorios y trabajos sobre entomología aplicada a realizar por el "Instituto Español de Entomología” durante el año $1955 »^{29}$. En el se recogen sus ideas acerca de cómo el IEE debiera estar organizado para ser un centro enfocado claramente a la realización de proyectos e investigaciones de tipo aplicado. En la propuesta, que incluyó el presupuesto de lo que costaría la restructuración, Ceballos recomendaba la creación de hasta cinco laboratorios:

Laboratorio de biología y ensayos en la Sierra de Guadarrama, con capacidad para almacenar materiales para los estudios;

Laboratorio de Química, con la construcción de un nuevo pabellón anexo al Insectario y donde «se llevaría a cabo el análisis y control de los productos comerciales y se procedería al estudio de nuevos productos o mezclas»;

Laboratorio biológico de comprobación, localizado también en el anterior futuro nuevo pabellón y que sería utilizado para «la cría de insectos perjudiciales y la comprobación en el laboratorio de los efectos letales de los insecticidas»);

Laboratorio de lucha biológica y enfermedades infeccionas, para la «catalogación, estudio y cría de parásitos de insectos perjudiciales [...] junto con el estudio de bacterias y virus» de los mismos);
Laboratorio de Sistemática, localizado en el propio edificio del IEE con el objetivo de "poder llegar a un conocimiento lo más perfecto posible de la fauna entomológica perjudicial y sus parásitos»).

La participación del IEE que Ceballos perseguía se resolvió con la firma de un Convenio de Colaboración entre el Consejo Superior de Investigaciones y el Servicio de Plagas Forestales ${ }^{30}$. En la carta del 11 de diciembre de 1957 que el Director del Servicio Especial de Plagas Forestales envía al Presidente del CSIC, José Ibáñez Martín, el Servicio justificaba la necesidad que tenía del apoyo del IEE «Algunas dificultades que el citado Servicio viene encontrando [...] son consecuencia en la mayoría de los casos, de falta de conocimiento exacto de las biologías de dichos agentes" y solicita que

El mencionado Instituto [IEE] pondría estos terrenos y edificios a disposición del personal técnico del servicio de Plagas Forestales, con dedicación concreta, y bien delimitada, garantizaría el mejor aprovechamiento de su trabajo y llegaría a proporcionarle una adecuada especialización quedando bien patente que por parte del Instituto sólo se trata de una prestación temporal,

mientras que «El servicio de Plagas Forestales atendería a todos los gastos dimanantes de los citados trabajos experimentales». El 16 de enero de 1958, el Vicesecretario del CSIC, José Royo, comunicó a Ceballos que la Comisión Permanente había acordado autorizar la propuesta de que el Servicio Especial de Plagas Forestales utilizara terrenos y edificios del IEE "a fin de poder seguir las evoluciones por las que pasan los insectos $»^{31}$. La relación del IEE con éste siempre fue muy estrecha; se contó por ejemplo, con la ayuda del Instituto para la formación de técnicos en 1956, cuando envían personal al Instituto para «practicarse en los trabajos de preparación, conservación y cultivos de carácter entomológico...»32.

La reestructuración del IEE que Ceballos demandaba nunca se llevó a cabo pues solo el Laboratorio de lucha biológica y enfermedades infecciosas se puso en marcha bajo la codirección del mismo Instituto y del recién creado Servicio Especial de Plagas Forestales. El fallecimiento de Eduardo Zarco en 1957 muy probablemente supuso un grave contratiempo en los planes de Gonzalo Ceballos pues era su más estrecho colaborador y seguramente también se sumó a esta pérdida la disminución de presupuestos que el CSIC experimentó en los años del Plan Nacional de Estabilización Económica de 1959 (Malet, 2008). La gestión de este «Laboratorio de Patología de Insectos y Biocenosis» fue encomendada al ingeniero de montes Adolfo Rupérez Cuéllar, 
que entonces trabajaba como entomólogo en la Sección de Estudios del Servicio, quien pasó a encargarse de «la organización y desarrollo de la lucha biológica ${ }^{33}$. Un repaso de lo que se realizaba en este Laboratorio lo encontramos relatado por el propio Rupérez en el número 3 del Boletín del Servicio de Plagas Forestales (Rupérez Cuellar, 1959), mirada que deja constancia del protagonismo del IEE en el combate que se mantiene en el ámbito de las plagas forestales:

... el Instituto Español de Entomología, de una parte, consideró de interés el funcionamiento en nuestro país de un laboratorio que se ocupara de dicha labor [valoración de patogeneidad y seguridad sanitaria] de prospección y experimentación, y a tal efecto se ha establecido un trabajo en colaboración entre dicho Instituto y el Servicio de Plagas Forestales, este último interesado, por otra parte, en el tratamiento por medios biológicos de las plagas de los montes. Esta modalidad de trabajo constituye un notable éxito económico, al reducir los gastos de investigación que podrían haberse producido de trabajar independientemente cada organismo citado (Rupérez Cuellar, 1959).

En el Laboratorio se estudiaban microorganismos que pueden producir enfermedades en los insectos, por ejemplo en la procesionaria (Thaumetopoea pityocampa Schiff.), plaga forestal que ya se había tratada en el IEE con anterioridad. La colaboración con el Servicio Especial de Plagas Forestales trae consigo la ampliación y modernización del espacio que ocupan en el Insectario ${ }^{34}$.

En la reestructuración del IEE solicitada también se proyectaba la publicación de una nueva revista sobre plagas «que lleve por nombre: REVISTA DE ENTOMOLOGÍA APLICADA» y un Boletín trimestral donde se reuniría información y bibliografía extranjera sobre Entomología Aplicada ${ }^{35}$. Curiosamente, el IEE ya disponía de una revista, Graellsia, serie que en el momento de su planificación se sugirió fuese creada para dar visibilidad a los trabajos de tipo aplicado; entonces no se hizo y tampoco fue propuesta su reorientación en el proyecto de Ceballos. El Servicio Especial de Plagas Forestales fue quien editó una revista que acogía obras de su interés, el Boletín del Servicio de Plagas Forestales, cuyo no 1 apareció en 1958.

Bajo la dirección de Gonzalo Ceballos se realizaron en paralelo estudios tanto de investigación aplicada como básica, justificando este maridaje en las Memorias anuales que remite al CSIC, «Dada la complejidad de los problemas entomológicos es sumamente difícil trazar una línea que separe taxativamente los aspectos de investigación pura de la aplicada» ${ }^{36}$. En estas Memorias se hace patente la colaboración con el «La- boratorio de Patología de Insectos», instalación que, recordemos, ocupaba el que antes fuera edificio del Insectario. En ellas se enumeran los estudios y trabajos del personal del Servicio:

trabajos y estudios fuera de España realizados por los Colaboradores del Servicio Especial de Plagas Forestales, D. Pedro Ceballos Jiménez y D. Adolfo Rupérez Cuellar, en el Museo de Historia Natural de Ginebra y en los Laboratorios de Lucha Biológica de la Minière, Antibes y Alés, respectivamente ${ }^{37}$.

Queda también recogido cuando el propio Director del Servicio Especial de Plagas Forestales pidió a Ceballos que Ramón Agenjo, entomólogo del IEE, fuera al Museo de Ciencias Naturales de París a estudiar Sesiidae para «resolver las arduas cuestiones taxonómicas ${ }^{38}$ del grupo o cuando Ceballos solicitó autorización al Presidente del Instituto Nacional de Investigaciones Agronómicas para que Adolfo Rupérez, del Servicio de Plagas, utilizara el microscopio electrónico ${ }^{39}$.

Ceballos dejó constancia de la importancia de la colaboración con el Servicio Especial de Plagas Forestales al subrayar que la patología de insectos era una «especialidad que no ha sido objeto de atención en España hasta ahora $»^{40}$. Las labores que el IEE resumió en sus Memorias desde 1960 a $1965^{41}$ fueron la participación, junto al Servicio Especial de Plagas Forestales, en proyectos sobre agentes patógenos con el fin de proteger a «insectos útiles como el gusano de seda y la abeja, y también para utilizar estos microorganismos contra los insectos perjudiciales de los cultivos y bosques»; el aislamiento de hongos patógenos y estudio de bacterias; el descubrimiento de "un virus poliédrico en orugas de Catocala nymphaea Esp. (Lep. Noctuidae), nuevo para la Ciencia y que permite estudiar la posibilidad de un control biológico contra este perjudicial lepidóptero de los encinares»; el uso de Bacillus thuringiensis (bacterias), Smithiavirus pityocampae (virus) y Borrelina reprimens (virus) que había servido para «llevar a la práctica diversos tratamientos en los montes con suspensiones patógenas contra insectos perjudiciales, tales como la procesionaria del pino (Thaumetopoea pityocampa Schiff.) y lagarta peluda (Lymantria dispar L.)»; la colaboración en «una campaña de prospección en el Pirineo de las especies de Formica del grupo rufa, con el fin de localizar dichas especies de hormigas que, estudiadas in situ y en el laboratorio, dejaran ver sus posibilidades de utilización como predatores de las orugas de "procesionarias"». El IEE también cooperó con la Sección de Bioquímica del Instituto de Investigaciones Agronómicas sobre el biomio insectos-levaduras y la acción esterilizante de las radiaciones gamma sobre insectos. 


\section{CONCLUSIONES}

La idea de que la colaboración entre entomólogos especialistas en investigación básica y técnicos en entomología aplicada enriquecería las actuaciones de ambos sectores fue ya sugerida por Ignacio Bolívar, años antes de ser creado el Instituto Español de Entomología. De hecho, sirvió de justificación para solicitar la colaboración oficial de Gonzalo Ceballos con la Sección de Entomología del MNCN en el año 1928. No cabe duda de que la elección de Ceballos como director del IEE supuso para este Instituto una excelente oportunidad de ser un centro que participara, junto a las instituciones encargadas de la gestión forestal, en la lucha contra las plagas forestales; además, esta orientación hacia temas aplicados fomentaría el cumplimiento de los objetivos con los que el IEE fue concebido. Las actuaciones de Ceballos, una vez elegido Director del IEE, siguieron las propuestas de su maestro Ignacio Bolívar, considerando de gran interés, tanto para la Ciencia pura como para la aplicada, la estrecha colaboración entre ambas vertientes.

A lo largo de los años de dirección de Ceballos hemos identificado tres formas de participación en el estudio, gestión y control de plagas forestales. En primer lugar el servicio que realizó el IEE resolviendo consultas de instituciones, empresas y particulares con la identificación de insectos que pueden causar daños. Son dictámenes puntuales que incluyen la determinación taxonómica de los ejemplares, informe de su biología, distribución, potencialidad como plaga y su erradicación y control preventivo. Se realizaron en los primeros años del IEE y los especialistas que resolvieron estas consultas fueron Gonzalo Ceballos, Eduardo Zarco, Ramón Agenjo y José del Cañizo.

En un segundo grupo de actividades reunimos los proyectos que llevaron a cabo directamente Ceballos y Zarco, gracias a las subvenciones del Patronato Juan de la Cierva, como son el dirigido al estudio de las Plagas de insectos en los viveros forestales, el control en pinares de la lagarta (especies del género Lymantria) y del himenóptero Diprion pini (L.), con fumigaciones de áreas afectadas, el desarrollo de dispositivos para la dispersión de insecticidas, etc. Es destacable también la elaboración de materiales divulgativos dirigidos a la formación de diferentes colectivos, tanto de agricultores como de técnicos.

En tercer lugar encontramos la implicación de Gonzalo Ceballos impulsando la restructuración de las instituciones del Ministerio de Agricultura para acometer el estudio y control de las plagas forestales. El interés de Ceballos por la investigación y tratamiento de estas plagas se tradujo en la promoción de un Servicio que únicamente se dedicase a ello, el Servicio Especial de Plagas Forestales. Los cambios que Ceballos pretendió se realizasen en el IEE indican su interés por potenciar las investigaciones de tipo aplicado en éste, queriendo poner a disposición del recién creado Servicio, unos laboratorios que serían controlados desde el Instituto. Ceballos continuó la colaboración con la cesión de instalaciones, como son la Estación de Ensayos Biológicos de El Ventorrillo o el Insectario, parcialmente ocupado por el Laboratorio de Patología de Insectos del Servicio Especial de Plagas Forestales. El personal que en esa época trabajaba en el IEE no participaba directamente en las labores relacionadas con las plagas, aunque sus investigaciones girasen en torno a especies de insectos que podían originar daños como plagas. Su aportación en este sentido puede ser cuantificada valorando que en el Boletín de Plagas Forestales, hasta 1967, se publicaron 188 artículos, de los cuales casi el $20 \%$ son atribuibles a personal del IEE, en concreto a Gonzalo Ceballos, Ramón Agenjo y Francisco Español.

En resumen, muy probablemente la falta de personal especializado en plagas realmente adscrito al IEE supuso un grave inconveniente para que las diferentes iniciativas de Ceballos tuvieran continuidad a lo largo del tiempo. En los primeros años se esforzaron en incorporar estudios de entomología aplicada a las líneas de investigación del instituto, impulso que decayó tras la muerte en 1958 del colaborador más estrecho de Ceballos, Eduardo Zarco. A partir de entonces, aunque desde el centro se siguiera insistiendo en su vinculación con las investigaciones de tipo aplicado, mencionado por ejemplo estudios de insectos con interés forestal, el hecho es que los trabajos volvieron a estar dirigidos fundamentalmente hacia temas básicos como la taxonomía, sistemática, ciclos biológicos y corología. El Servicio Especial de Plagas Forestales que en 1964 era el «único organismo dedicado con exclusividad a las plagas forestales» y en el cual «recae toda la investigación encaminada a la defensa de los montes contra las plagas y enfermedades» (Torrente \& Romanyk, 1964) quedó desde entonces como principal encargado del tema.

En 1967 a Ceballos sucedió como Director el entomólogo Ramón Agenjo. Ese mismo año se produjo una restructuración de las secciones y perso- 
nal del IEE, asumiendo éste una gran parte de los investigadores del Departamento de Zoología del Suelo del Instituto de Edafología y Biología Vegetal del $\mathrm{CSIC}^{42}$. La entomología forestal quedó entonces olvidada y los insectos productores de plagas, esa «multitud molesta» como la denominaba Ceballos, dejó de ser objeto de estudio en el Instituto Español de Entomología, quedando éste como un centro dedicado casi en exclusiva a la investigación entomológica pura.

\section{NOTAS}

1 Trabajo financiado por el Proyecto HAR 2011-28621 del antiguo Ministerio de Ciencia e Innovación.

2 Decreto de 10 de marzo de 1941 por el que se crea en el Consejo Superior de Investigaciones Científicas el Instituto Español de Entomología. Boletín Oficial del Estado, de 22 de marzo de 1941 (81), pág. 1932-1933.

3 CSIC, Memoria de 1940-1941, pág. 90.

4 CSIC, Memoria de 1940-1941, pág. 90.

5 R.D. de 10 de noviembre de 1922, Gaceta de Madrid, de 11 de noviembre de 1922 (315), pág. 546.

6 Véase OTERO CARVAJAL \& LÓPEZ SÁNCHEZ (2012), págs. 694-695 y AHMNCN, Fondo Museo, serie Administración, caja 011.

7 Véase OTERO CARVAJAL \& LÓPEZ SÁNCHEZ (2012), págs. 694-695 y AHMNCN, Fondo Museo, serie Administración, caja 013.

8 Actualmente Malabo, Bioko (Guinea Ecuatorial).

9 Carta de Luis Báguena al director del IEE de fecha 1 de enero de 1942 desde Santa Isabel, Fernando Poo, Guinea Española (AHMNCN, ACN0544-008)

10 Véase, CSIC, Patronato Juan de la Cierva, Memoria de 1948, pp. 194-195.

11 Oficio de 30 de julio de 1943, del alcalde del Ayuntamiento de Burgos dirigido al director del IEE (AHMNCN, ACN0464) y minuta de respuesta de 9 de agosto de 1943 del director del IEE al Ayuntamiento de Burgos (AHMNCN, ACNO456).

12 Minuta del oficio de 26 de julio de 1947 del director del IEE, remitiendo informe al Capitán General de Madrid (AHMNCN, ACN0456)

13 Entomólogo especializado en coleópteros. Secretario del IEE hasta su fallecimiento en 1957.

\section{AGRADECIMIENTOS}

Agradecemos a $\mathrm{M}$ a Cruz Osuna su excelente trabajo como documentalista y también, como a Ana Isabel Camacho, la lectura crítica del manuscrito. Alfonso Navas y Lee Robertson nos han ayudado con la revisión del inglés. Los evaluadores con sus comentarios nos han ayudado a mejorar el trabajo. Damos igualmente las gracias al personal de Biblioteca y Archivo del MNCN por su apoyo y buen hacer en todas las consultas que les hemos realizado.

14 Informe remitido por el director del IEE al secretario del Patronato Juan de la Cierva el 2 de septiembre de 1946 (AHMNCN, ACN0446).

15 Informe remitido por el director del IEE al secretario del Patronato Juan de la Cierva el 26 de diciembre de 1946 (AHMNCN, ACN0446)

16 Véase la correspondencia con ingenieros de los Distritos Forestales sobre los trabajos relacionados con plagas forestales y subvencionado por el Patronato Juan de la Cierva entre 1946 y 1951 (AHMNCN, Fondo Personal Científico Gonzalo Ceballos, P48).

17 Informe sobre el lepidótero Lymantria monacha presentado por el director del IEE al [secretario del Patronato Juan de la Cierva] el 10 de septiembre de 1951 (AHMNCN, ACN0446).

18 Oficio del director de la Escuela de Ingenieros Industriales al director del IEE, de 16 de octubre de 1947, comunicando la realización de obras cerca del insectario del Instituto (AHMNCN, ACN0464).

19 CSIC, Memoria del Patronato Juan de la Cierva de 1950, p. 271.

20 Informe sobre el lepidótero Lymantria monacha presentado por el director del IEE al director general de Montes, Caza y Pesca Fluvial el 12 de marzo de 1951 (AHMNCN, ACN0457).

21 Informe sobre el lepidótero Lymantria monacha presentado por el director del IEE al [secretario del Patronato Juan de la Cierva] el 10 de septiembre de 1951 (AHMNCN, ACN0446).

22 Expediente Filmoteca 29804. Título: Plaga forestal en la sierra de Albarracín. Cortometraje, $16 \mathrm{~mm}, 4$ minutos.

23 Informe presentado por el director del IEE al Presidente de la Comisión Asesora de Investigación Científica y Técnica, el nueve de abril de 1958 (AHMNCN, ACN0457).

24 CSIC, Memoria de 1955-1957, pp. 343-344. 
25 Graellsia, vol. 15 (1957) dedicado a la Entomología forestal.

26 Informe acerca de los trabajos realizados sobre entomología forestal, remitido por el director del IEE al vicesecretario del Patronato Juan de la Cierva, el 8 de Julio de 1958 (AHMNCN, ACN0457).

27 Informe acerca de los trabajos realizados sobre entomología forestal, remitido por el director del IEE al vicesecretario del Patronato Juan de la Cierva, el 6 de octubre de 1958 (AHMNCN, ACN0457).

28 Informe acerca de los trabajos de entomología forestal, realizados en el cuarto trimestre de 1957, remitido por el director del IEE al vicesecretario del Patronato Juan de I Cierva, el 24 de enero de 1958 (AHMNCN, ACN0457).

29 "Proyecto de Organización de Laboratorios y Trabajos sobre Entomología Aplicada a realizar por el Instituto de Entomología durante el año 1955", de 21 de abril de 1955. (AHMNCN, ACN0457).

30 Copia del Convenio de colaboración del Instituto Español de Entomología con el Servicio Especial de Plagas Forestales (Ministerio de Agricultura, Dirección General de Montes, Caza y Pesca Fluvial), de 9 de enero de 1958 (AHMNCN, ACN0451/005).

31 Traslado del acuerdo de la Comisión Permanente del CSIC al director del Servicio Especial de Plagas Forestales, de 16 de enero de 1958, sobre autorización del uso de terrenos y edificio del IEE (AHMNCN, ACN0465).

32 Oficio del director del Servicio Especial de Plagas Forestales al secretario del IEE, de 11 de octubre de 1956, presentan-

\section{BIBLIOGRAFÍA}

Agenjo, Ramón (1967), “El Excmo e Ilmo Sr. Prof. Dr. D. Gonzalo Ceballos y Fernández de Córdoba, 1895-1967", Eos 43, pp. 319-343.

Anónimo (1928), [Sin título], España Forestal, 145-146, p. 96.

Anónimo (1953), "Las plagas del campo son atacadas desde el aire", Boletín Informativo del Instituto de Ingenieros Civiles de España, 2, p. 13.

Cadahia Cicuendez, Domingo (1958), "Los Aegeridae y los chopos", Graellsia, 16, pp. 59-74.

Ceballos, Gonzalo (1941), Idea general de la plaga producida por insectos. Escuela Especial de Ingenieros de Montes (inauguración de curso de 1941-1942), p. 38.

Ceballos, Gonzalo (1950), "Plagas forestales". En: Memorias de las actividades desarrolladas por el Patronato "Juan de la Cierva" de Investigación Técnica, año 1949. Madrid, Consejo Superior de Investigaciones Científicas, 211-213 (212). do al personal que envía para colaboración eventual en los trabajos de plagas forestales (AHMNCN, ACN0465).

33 Copia del oficio remitido por el director del Servicio Especial de Plagas Forestales al entomólogo Adolfo Rupérez Cuellar, de 4 de enero de 1958, sobre las funciones que debe desempeñar dentro del Servicio (AHMNCN, ACN0446).

34 CSIC, Memoria de 1959 p. 109.

35 Hasta 1958 no se publica el primer número del Boletín del Servicio de Plagas Forestales.

36 Informe presentado por el director del IEE al Presidente de la Comisión Asesora de Investigación Científica y Técnica, el 9 de abril de 1958 (AHMNCN, ACN0457).

37 CSIC, Memoria de 1959, p. 110.

38 Traslado que hace el director del IEE al entomólogo Ramon Agenjo, de la comunicación del director del Servicio Especial de Plagas Forestales, el 13 de abril de 1959, sobre el estudio de colecciones entomológicas (AHMNCN, ACN0457).

39 Solicitud del director del IEE al presidente del Instituto Nacional de Investigaciones Agronómicas de 14 de junio de 1960, para que autorice de utilización de un microscopio a un entomólogo del Instituto (AHMNCN, ACN0457).

40 CSIC, Memoria de 1960, p. 111

41 CSIC, Memoria de 1960, 1961-1962; Memorias IEE de 1963, 1964 y 1965 (AHMNCN, ACN0433 y ACN00448)

42 Instituto Español de Entomología, Memoria del año 1967 (AHMNCN, ACN0459).

Ceballos, Gonzalo \& Zarco, Eduardo (1952), Ensayo de lucha biológica contra una plaga de Diprion pini (L.) en masas de Pinus silvestris, de la Sierra e Albarracín. Trabajos del Patronato Juan de la Cierva, Instituto Español de Entomología, CSIC.

Gómez-Menor Guerrero, Juan Miguel (1957a), “Biocenosis en las agallas del chopo", Graellsia, 15, pp. 175-186.

Gómez-Menor Guerrero, Juan Miguel (1957b), “Datos biológicos del Ecacanthothrips nodicornis (Reut.)", Graellsia, 15, pp. 187-192.

Gomis, Alberto (2014), “Mimbres para otro cesto: De la Sección de Entomología del Museo Nacional de Ciencias Naturales al Instituto Español de Entomología", Boletín de la Real Sociedad española de Historia Natural, Sección Biología, 108, pp. 1-11, disponible en: http://147.96.59.157/rsehn/index. php?d=publicaciones\&num $=34 \& w=216 \quad$ [consultado el $11 / 11 / 2014]$ 
López García, Santiago (1997), “El Patronato Juan de la Cierva (1939-1960). I Parte: Las Instituciones Precedentes", Arbor, 619, pp. 202-238.

M.G.V. [Manuel García de Viedma] (1968a), “Excmo. Sr. Don Gonzalo Ceballos y Fernández de Córdoba 1895-1967", Boletin de Patología vegetal y Enomología argícola, 30, pp. 341-347.

M.G.V. [Manuel García de Viedma] (1968b), "In Memoriam Excmo. Sr. Don Gonzalo Ceballos y Fernández de Córdoba 18951967", Miscelánea Zoológica, 2 (3), pp. 179-184.

Malet, Antoni (2008). "Las primeras décadas del CSIC: investigación y ciencia para el franquismo". En: Romero de Pablos, Ana \& Santesmases, María Jesús (eds.), Cien años de política científica en España, Madrid, Fundación BBVA.

Notario Gómez, Antonio (2008), El devenir de la docencia e investigación de Zoología y Entomología en la carrera de Montes, Lección Inaugural del Curso Académico 2008-2009. Madrid, Escuela Técnica Superior de Ingenieros de Montes, Universidad Politécnica de Madrid.

Otero Carvajal, Luis Enrique \& López Sánchez, José María (2012), La lucha por la modernidad. Las Ciencias Naturales y la Junta para Ampliación de Estudios. Madrid, CSIC - Publicaciones de la Residencia de Estudiantes.

Pajares Alonso, Juan Antonio (2009), "Los médicos del monte: una mirada a la sanidad forestal española desde sus inicios hasta los nuevos escenarios del siglo XXI", 5o Congreso Forestal Español. Montes y sociedad: Saber qué hacer. Sociedad Española de Ciencias Forestales - Junta de Castilla La Mancha, pp. 1-17.
Rupérez Cuellar, Adolfo (1958), “Combate y reducción de Lymantria monacha en España", Boletín del Servicio de Plagas Forestales, 1 (2), pp. 95-107.

Rupérez Cuellar, Adolfo (1959), "Las enfermedades de los insectos", Boletín del Servicio de Plagas Forestales, 3, pp. 115121.

Soria, Santiago \& Cobos, José María (1990), “Aportaciones al conocimiento de la historia de la sanidad forestal española". En: Sesión homenaje al Profesor García de Viedma, Madrid, Escuela Técnica Superior de Ingenieros de Montes, Fundación Conde del Valle de Salazar.

Torrente, José Andrés \& Romanyk, Néstor (1964), “Las plagas forestales en España", Simposio FAO/IUFRO sobre Enfermedades e insectos forestales internacionalmente peligrosos. Tomo I. Oxford.

VVAA (1957), Trabajos de Entomología Forestal. Madrid, Instituto Español de Entomología, Trabajos del Patronajo Juan de la Cierva, CSIC.

Ximénez de Embún, Joaquín \& Ceballos, Luis (1996), “Plan General para la Repoblación Forestal de España”. En: Ceballos y Fernández de Cordoba, Luis, Tres Trabajos Forestales, Madrid, Publicaciones del Organismo Autónomo de Parques Nacionales, Ministerio de Medio Ambiente.

Zarco, Eduardo \& Ceballos, Gonzalo (1956), Insectos perjudiciales al chopo en España. Madrid, Servicio de Plagas forestales, Ministerio de Agricultura. 